\title{
Experiment on the Influence of Vertical Heterogeneity of Reservoir on the Steam Drive Effect
}

\author{
Pang Jin ${ }^{1, *}$, Yue Yixing ${ }^{1}$, Peng $\mathrm{Xu}^{2}$, Chen Guiping ${ }^{3}$ and Li lu ${ }^{4}$ \\ ${ }^{I}$ Department of Petroleum Engineering, Chongqing University of Science and Technology, Chongqing, 401331, \\ P.R.China; ${ }^{2}$ PetroChina Liaohe Oilfield Company, Panjin, Liaoning, 124000, P.R. China; ${ }^{3}$ CNPC Chuanqing Drilling \\ Engineering Company Limited, Chengdu, Sichuan, 610000, P.R. China; ${ }^{4}$ Geologic Exploration and Development Re- \\ search Institute, CNPC Chuanqing Drilling Engineering Company Limited, Chengdu, 610051, P.R. China
}

\begin{abstract}
This paper carried out experimental studies on the influence of vertical heterogeneity of reservoir on the steam drive effect after multiple-round steam stimulations. Taking the actual productive process of a heavy oil reservoir as an example, a physical model for the vertical heterogeneity was established. First, under the initial reservoir conditions, conduct multiple rounds of steam stimulations to obtain the initial reservoir conditions of steam drive, and then carry out physical simulation of steam drive, including the simulation of the horizontal reservoir and the tilted one. The development of temperature field and the oil-water output changes indicate that when the steam drive is conducted after the steam stimulations, the steam advances along the high permeability layer with better steam stimulation effect, once it gets a breakthrough, the swept volume will not change. For the tilted reservoir, due to the beneficial effects of the gravity drainage, its displacement effect is better than the horizontal one, which provides an important basis for the adjustment of layers and the section of methods of gas injection when the steam simulation is converted into steam drive.
\end{abstract}

Keywords: Experiment, Heterogeneity, Physical model, Steam drive, Steam stimulation, Vertical.

\section{INTRODUCTION}

The current experimental studies of indoor thermal recovery are mostly carried out for a particular development process, such as the steam stimulation, steam drive and SAGD (steam assisted gravity drainage), etc. [1-5], that is to conduct an experiment under the initial conditions of the reservoir. However, in China, to develop the heavy oil reservoirs, first we conduct the multi-cycle steam stimulation, and then turn to steam drive, and the reservoir conditions at this time are very different from the initial conditions [6-8]. In this process, the heterogeneity of the reservoir has an obvious influence on the steam drive effect. Therefore, it is necessary to make an organic combination of the steam stimulation and steam drive and establish a proportional physical simulation model. Then, on the basis of this model, conduct the experimental study of the influence of the reservoir heterogeneity on the steam drive effect and that of the development rule of steam chamber on the displacement effect under the vertical homogeneous conditions of the reservoir.

\section{EXPERIMENT PRINCIPLE}

In the proportional physical simulation model, the experimental model and the prototype are required to be consistent in geometrical conditions, physical conditions, boundary conditions and time conditions. Besides, the similarity criteria comprised by these conditions are numerically equal $[9,10]$. The establishment and selection of the similarity criteria are the basis of the proportional physical simulation.

*Address correspondence to this author at the Department of Petroleum Engineering, Chongqing University of Science and Technology, Chongqing, 401331, P.R. China; Tel: +86 15923207146; Fax: +86 023-65022047; E-mail: crab1981@126.com
Conduct investigation and demonstration of the simulation experiment of steam stimulation and steam drive and then study their similarity theory $[11,12]$ to establish the two-dimensional physical simulation model for the whole process of the heavy oil reservoir that the steam stimulation turns to the steam with the model parameters as shown in Table 1.

Table 1. Physical model parameters of steam drive.

\begin{tabular}{|c|c|c|c|}
\hline Parameters & Unit & Prototype value & $\begin{array}{c}\text { Model } \\
\text { value }\end{array}$ \\
\hline \hline Well spacing & $\mathrm{m}$ & 70 & 0.7 \\
\hline Permeability & $\mu \mathrm{m}^{2}$ & 1.49 & 149 \\
\hline Porosity & $\%$ & 25 & 37.6 \\
\hline Thermal diffusivity & $\mathrm{m}^{2} / \mathrm{s}$ & $9.87 \times 10^{-5}$ & $6.54 \times 10^{-5}$ \\
\hline Oil viscosity & $\mathrm{mPa} \cdot \mathrm{s}$ & 1535 & 1535 \\
\hline Oil density & $\mathrm{kg} / \mathrm{m}^{3}$ & 881.5 & 912.3 \\
\hline Steam density & $\mathrm{kg} / \mathrm{m}^{3}$ & 2.548 & 2.548 \\
\hline Gas injection temperature & ${ }^{\circ} \mathrm{C}$ & 280 & 150 \\
\hline Similarity ratio & & & 0.01 \\
\hline Time & $\mathrm{a}$ & 1 & $1.51 \mathrm{E}-04$ \\
\hline Pressure difference & $\mathrm{MPa}$ & 2.4 & 0.02483 \\
\hline Injection volume & $\mathrm{m}^{3} / \mathrm{d}$ & 135 & 2.0304 \\
\hline Mobility & & $9.70684 \times 10^{-5}$ & $9.37913 \times 10^{-6}$ \\
\hline
\end{tabular}


Based on the actual geometrical and physical properties of the reservoir, use the similarity criteria to establish the vertical heterogeneity model. It has a system of an injection well and a production well and simulates the profile between injection and production wells, as shown in Fig. (1). The model size is $70 \mathrm{~cm} \times 30 \mathrm{~cm} \times 3.5 \mathrm{~cm}$; simulation layers include 5 oil layers and 2 interlayers, a total of 7 layers, and the simulation parameters of each layer are as shown in Table 2. In the high-pressure physical model system, respectively conduct steam drive experiment for the horizontal vertical heterogeneous reservoir and the tilted vertical heterogeneous reservoir.

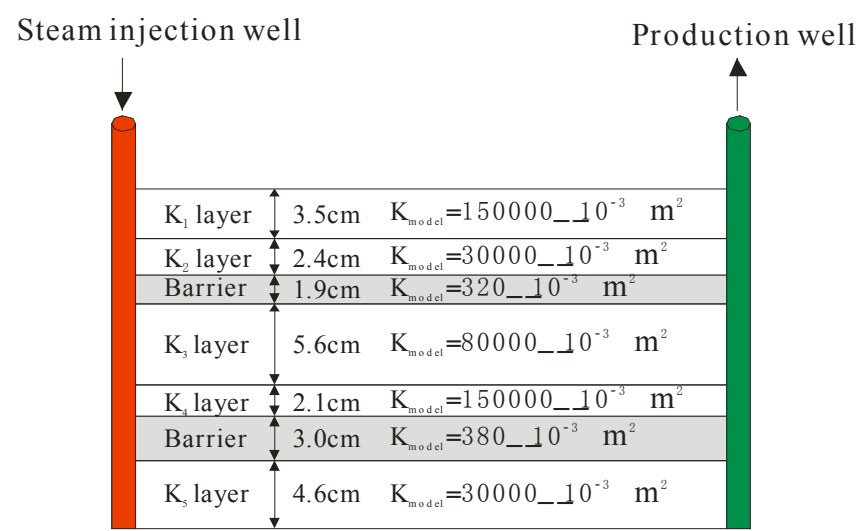

Fig. (1). Diagram of vertical heterogeneous reservoir model.

Table 2. Parameters of vertical heterogeneous reservoir model.

\begin{tabular}{|c|c|c|c|c|}
\hline \multirow{2}{*}{ Layer } & \multicolumn{2}{|c|}{ Reservoir } & \multicolumn{2}{c|}{ Model } \\
\cline { 2 - 5 } & Thickness (m) & $\begin{array}{c}\text { Permeability } \\
\left.\mathbf{( 1 0}^{-3} \boldsymbol{\mu ~ m}^{\mathbf{2}}\right)\end{array}$ & Thickness (m) & $\begin{array}{c}\text { Permeability } \\
\left(\mathbf{1 0}^{-3} \boldsymbol{\mu m}^{\mathbf{2}} \mathbf{)}\right.\end{array}$ \\
\hline \hline $\mathrm{K}_{1}$ & 3.5 & 1500 & 3.5 & 150 \\
\hline $\mathrm{K}_{2}$ & 2.4 & 3000 & 2.4 & 300 \\
\hline $\begin{array}{c}\text { Barri- } \\
\text { er }\end{array}$ & 1.9 & 3.2 & 1.9 & 0 \\
\hline $\mathrm{K}_{3}$ & 5.6 & 800 & 5.6 & 80 \\
\hline $\mathrm{K}_{4}$ & 2.1 & 1500 & 2.1 & 150 \\
\hline $\begin{array}{c}\text { Barri- } \\
\text { er }\end{array}$ & 3.0 & 38 & 3.0 & 0 \\
\hline $\mathrm{K}_{5}$ & 4.6 & 300 & 4.6 & 30 \\
\hline
\end{tabular}

\section{THE EXPERIMENTAL DEVICE}

The experiment was conducted in a high-pressure plane physics model with the experiment process shown in Fig. (2). The physical simulation system consists of the injection system, model system, constant temperature system, signal detection system, recovery system, data acquisition and processing system.

The injection system is used for fluid injection, consisting of high-pressure constant speed pump, steam generators, intermediate container, pipe valves and other components.
The constant temperature system consists of temperature control instrument, heater and insulation sleeve. It is used to heat the model and simulate the temperature of reservoir formation. The controllable room temperature range of highpressure plane model is $\sim 150{ }^{\circ} \mathrm{C}$.

The data acquisition and processing system consists of a computer, data acquisition modules and data acquisition card, and it is used for the acquisition and storage of the temperature and pressure signal of the model, including the real-time monitoring of the changes in the temperature and pressure of each measuring point, and the processing of the temperature field diagram and pressure curve at each moment.

\section{THE EXPERIMENTAL PROCEDURES}

(1) The processing of the inner wall of the model

Install the pressure-proof insulating board at the bottom of and around the model for heat insulation.

(2) The installation of well pipe and thermocouple

For the shaft, adopt the stainless steel pipeline with a diameter of $6 \mathrm{~mm}$ and slot at the position of the oil layer to simulate the perforated interval of the site well.

The vertical heterogeneous model has 7 simulation layers and each layer has 15 thermocouples, a total of 105 .

\section{(3) Model filling}

Before the model filling, it is necessary to develop the model sand with different particle sizes according to a certain ratio, aiming to make its permeability and the calculated permeability equal. Use the water injection settlement to fill the model, and then tighten the lid to conduct the leak test with the pressure of $0.70 \mathrm{MPa}$. If the pressure will not decrease in $1 \mathrm{~h}$, it passes the test.

\section{(4) Saturated water}

Discharge the water in the model, inject the ethanol with the doubled volume, and dry it with nitrogen. Then access it to the evacuation procedure, and when the vacuum reaches 133.3 $\mathrm{Pa}$, continue the evacuation for $5 \mathrm{~h}$. Saturate the experimental water and calculate the pore volume and porosity of the model according to the volume of the saturated water.

\section{(5) Saturated oil}

Adjust the model to be horizontal and access it to the saturated oil procedure. Inject the oil used in the experiment into the model at a constant low speed to conduct displacement of water with oil and then calculate the volume of the water at each outlet to make the oil be fully and evenly saturated. Calculate the total volume of the water, coupled with the saturation degree of the initial oil and bound water after there is no more water at the outlet and the pressure becomes stable.

\section{(6) Steam stimulation}

According to the site production, simulate the steam stimulation process, and when the degree of recovery reaches $24 \%$ and the formation pressure drops to $4.0 \mathrm{MPa}$, stop simulation. Carry out a total of 8 cycles of stimulation. 


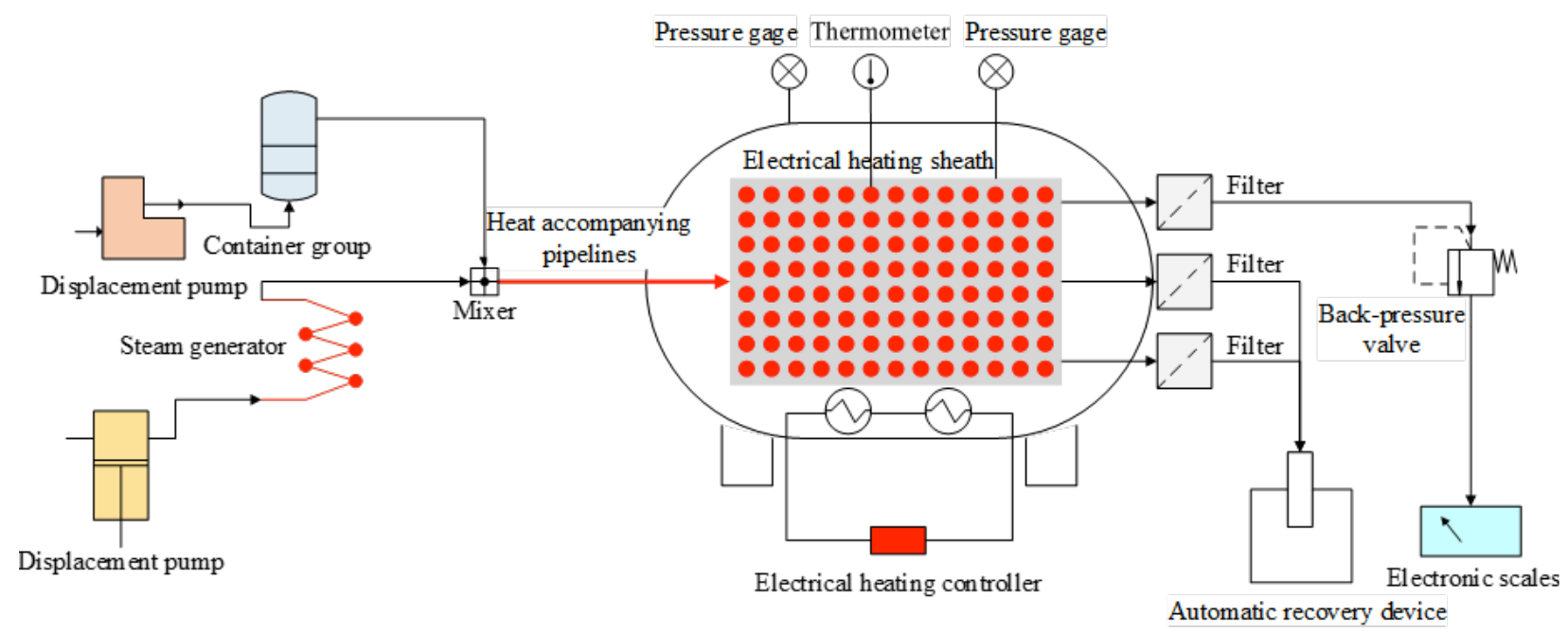

Fig. (2). Experimental flowchart.

\section{(7) Steam drive simulation}

After the steam stimulation, conduct the steam drive simulation. The experimental parameters calculated by the similar proportions of steam drive are as shown in Table $\mathbf{3}$. In this process, record the temperature at each temperature measurement point at different moment and the water production and oil production of each simulated production wells.

The experiment is divided into two parts: the steam drive of horizontal reservoir, and then clean the reservoir model and tilt it by $18^{\circ}$. Repeat step (4) to (7) and then conduct steam drive experiment for the tilted reservoir.

Table 3. Prototype and model parameters of steam drive.

\begin{tabular}{|c|c|c|}
\hline Parameters & Reservoir & Model \\
\hline \hline $\begin{array}{c}\text { Reservoir pressure when the steam } \\
\text { drive begins }\end{array}$ & $4.0 \mathrm{MPa}$ & $0.475 \mathrm{MPa}$ \\
\hline Well temperature & $40^{\circ} \mathrm{C}$ & $18^{\circ} \mathrm{C}$ \\
\hline Steam injection temperature & $280^{\circ} \mathrm{C}$ & $150^{\circ} \mathrm{C}$ \\
\hline Steam injection speed & $135 \mathrm{~m}^{3} / \mathrm{d}$ & $3.42 \mathrm{~L} / \mathrm{h}$ \\
\hline Steam dryness & $50 \%$ & $50 \%$ \\
\hline Producing pressure drop & $3.0 \mathrm{MPa}$ & $0.03 \mathrm{MPa}$ \\
\hline
\end{tabular}

\section{RESULTS}

(1) The steam drive of horizontal vertical heterogeneous reservoir

In the horizontal vertical heterogeneous reservoir model, the producing degree between layers in steam stimulations are vastly different. High permeability layers on the top have good producing and those in the middle are also involved in producing, but the low permeability layers on the bottom barely have no producing, displaying significant steam overlaying feature. There are also some slight differences of producing degree within layers, as shown in Fig. (3). Different fluid distribution areas including the steam zone, hot water zone, and reservoir fluid zone are formed from around the wellbore to the deep area of reservoir between two wells.

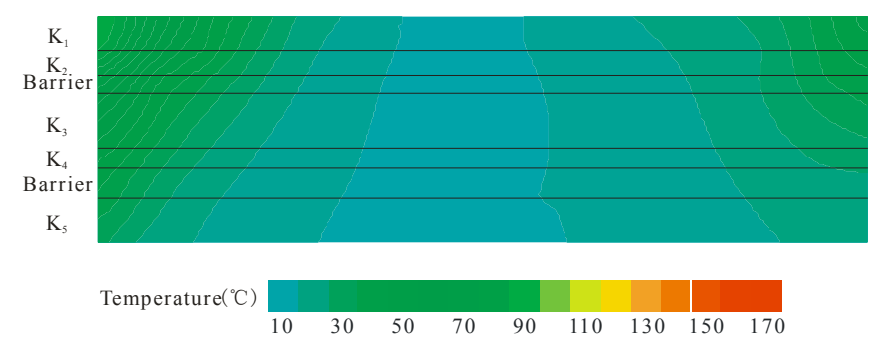

Fig. (3). Temperature field distribution of vertical heterogeneous model at the end of steam stimulation.

After converting to steam drive, steam first advances along the high permeability layer at the top that has good producing in steam simulation phase. With the injection of steam, oil temperature gradually increases and the high permeability layer in the middle gradually gets better utilized. However, the low permeability layer in the lower part does not get well used until the end of steam drive, as shown in Fig. (4). This indicates that small layers have significantly different steam absorption in the steam drive process of vertical heterogeneous reservoir. Layers with better producing effects in steam simulation still have the same performance in the steam drive phase, and it is easy for the steam to make a breakthrough, thus leading to low displacement volume.

The recovery degree at the steam stimulation stage is $16.60 \%$ recovery, that at the steam drive stage is $30.07 \%$, and the final recovery degree is $46.67 \%$. Judging from moisture curve, there is a decline when the steam drive stage begins, but the time is short. Then it rises to more than $90 \%$ and keeps stable for a long period. When the steam gets a breakthrough, the moisture content is up to $99 \%$ until the end of steam flooding, as shown in Fig. (5). Compared with the site conditions, there may be some differences in the laws. When the steam drive begins, as there is a lot of water at the bottom of the well after steam simulation, the moisture content first rises and then falls, and then maintains at a relative- 
ly stable level. The analysis indicates that the indoor experimental model is small and the water rise does not last long, so it is difficult to conduct measurement. In addition, under condition of vertical heterogeneous reservoir, the steam first gets the breakthrough at the high-permeability layer, which leads to the slow expansion of the steam chamber and the moisture content keeps at $90 \%$ for a long time.
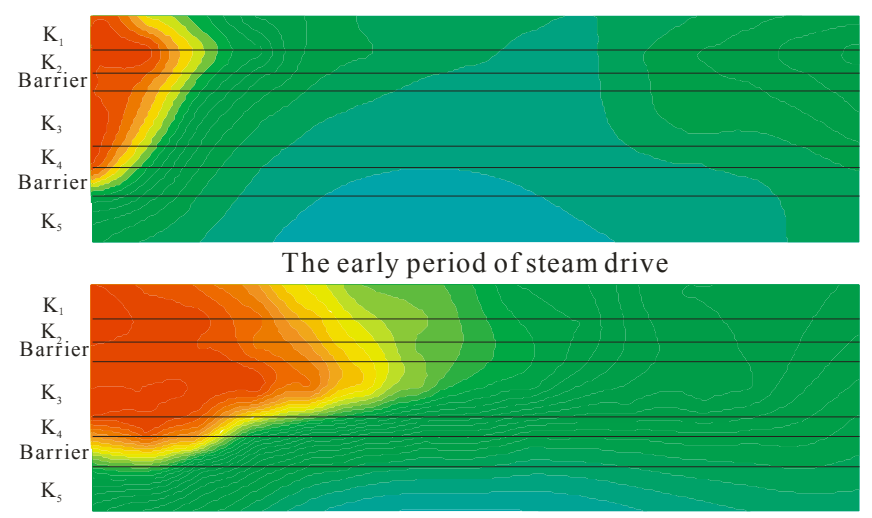

The middle period of steam drive

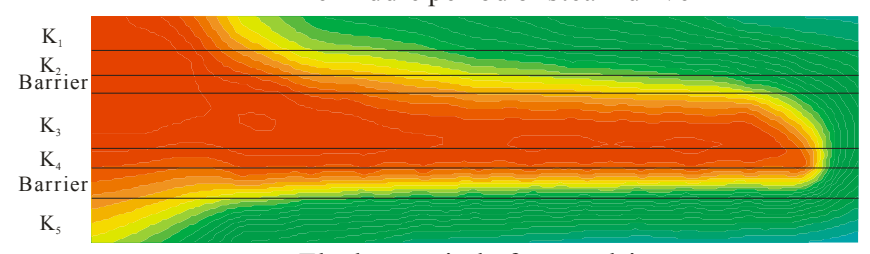

The last period of steam drive

Temperature $\left({ }^{\circ} \mathrm{C}\right)$

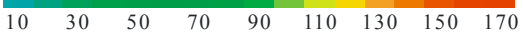

Fig. (4). Development of the temperature field of the steam drive of vertical heterogeneous model.

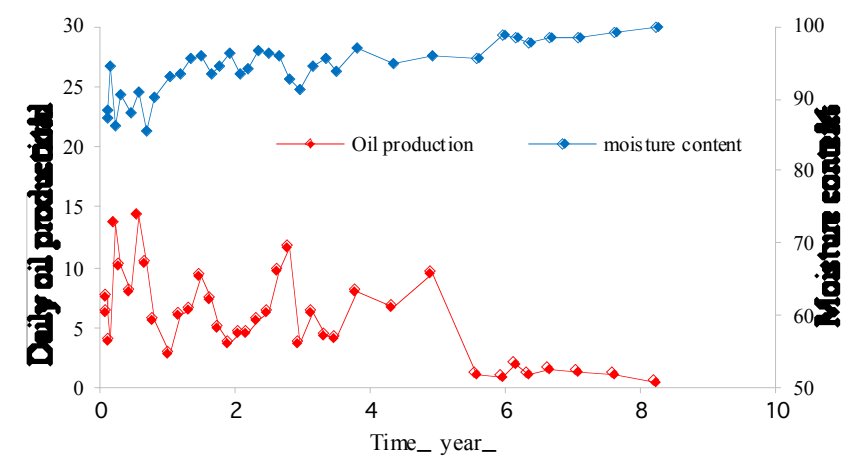

Fig. (5). The production curve of vertical heterogeneous reservoir at the steam drive stage.

(2) The steam drive of the tilted vertical heterogeneous reservoir

When the tilted vertical heterogeneous reservoir has a tilt angle of $18^{\circ}$, the situation at the steam stimulation stage is basically the same to that when its tilt angle is $0^{\circ}$. The top high-permeability layer has better production, followed by the one at the middle layer; while for the one at the bottom, there is almost no production, as shown in Fig. (6).

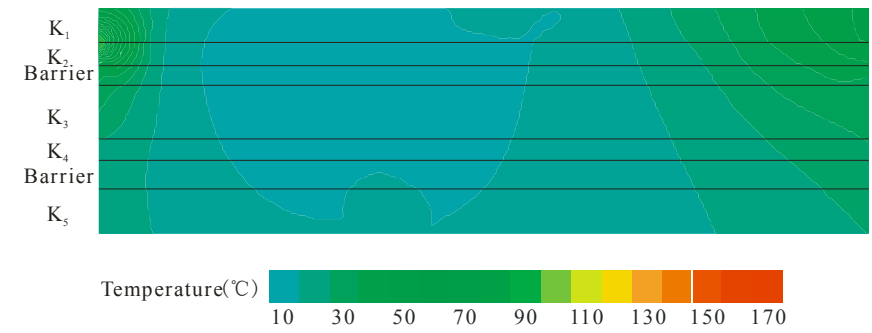

Fig. (6). Temperature field at the steam stimulation stage when the vertical heterogeneous reservoir has a tilt angle of $18^{\circ}$.

When the reservoir has a tilt angle of $18^{\circ}$, in the steam drive process, the steam first advances along with the highpermeability layer at the upper layer with better production. With the injection of steam, the oil temperature gradually increases and the one at the middle layer begins to get better utilized. In the late period, as the temperature of the lowpermeability layer increases, it is used gradually and finally gets better production, as shown in Fig. (7).
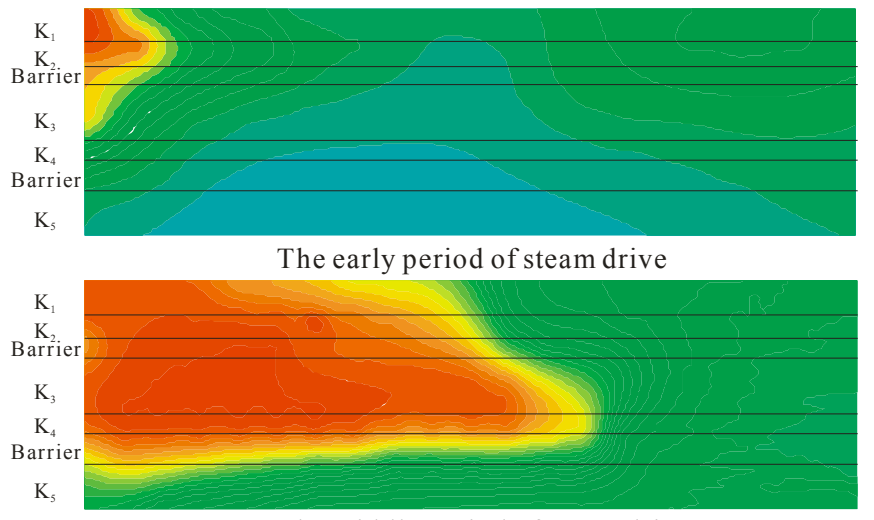

The middle period of steam drive

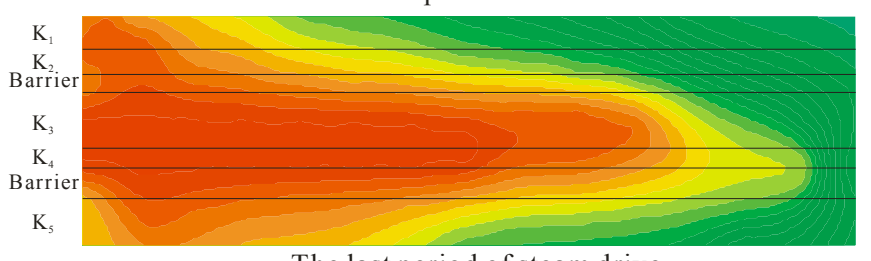

The last period of steam drive

Temperature $\left({ }^{\circ} \mathrm{C}\right)$

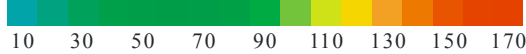

Fig. (7). Temperature field at the steam drive stage when the vertical heterogeneous reservoir has a tilt angle of $18^{\circ}$.

When the reservoir has a tilt angle of $18^{\circ}$, the recovery degree at the steam simulation stage is $17.62 \%$, while that at the steam drive stage is $36.1 \%$, and the final recovery degree is $53.72 \%$. Compared with the horizontal strata, the recovery degree when the reservoir has a tilt angle of $18^{\circ}$ is higher by $7.05 \%$. At the steam drive stage, the recovery degree is higher by $6.03 \%$, as shown in Fig. (8).

The comparison of the steam drive results when the tilt angle is $0^{\circ}$ and $18^{\circ}$ indicates that when the reservoir has vertical heterogeneity, the tilt angle is conducive to the lowerpermeability layer. The reason is that the long-time steam injection could heat the low-permeability layer, so its temperature rises, and then the oil viscosity decreases. Due to the big tilt angle, the location of production well is lower 
than the steam injection well, the oil's flowing ability increases due to the gravity, and it is recovered by the recovery well under the repeated effect of injected steam.

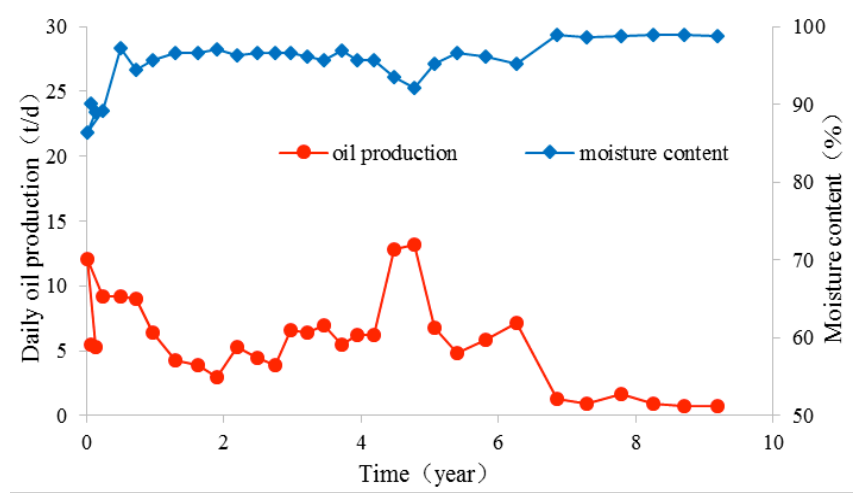

Fig. (8). The production curve at the steam drive stage when the reservoir has a tilt angle of $18^{\circ}$.

\section{CONCLUSION}

In the horizontal vertical heterogeneous reservoir, when the steam drive is conducted after the steam stimulations, the steam advances along the high permeability layer, forming the steam breakthrough. It is difficult for the remaining oil in the low-permeability layer to be involved, so it is suggested that the hierarchical steam injection or profile control could be adopted in the subsequent steam drive process to improve the production of high-permeability layer and lowpermeability layer.

In the tilted vertical heterogeneous reservoir, when the steam drive is conducted after the steam stimulations, the steam advances along the high permeability layer in the early period. With the injection of steam, the lateral diffusion of steam is conducive to heating the low-permeability layer. Under the action of dual displacement, the heat and gravity, the low-permeability layer also can get a better use.

To select the steam injection ways of the vertical heterogeneous reservoir, it is necessary to choose the separate injection or commingled injection according to the tilt angle and heterogeneity coefficient of reservoir, aiming to improve the efficiency of steam drive.

\section{CONFLICT OF INTEREST}

The authors confirm that this article content has no conflict of interest.

\section{ACKNOWLEDGEMENTS}

Declared none.

\section{REFERENCES}

[1] S.M. Al-Hinai, H. Al-Shureq, and J.N.M.V. Wunnik, "Steam flooding a thick heavy oil reservoir: development of numerical tools for reservoir management," In: SPE EOR Conference at Oil \& Gas West Asia, Muscat, Oman, 2010.

[2] W.J. Al-Mudhafer, "The use of thermodynamic reservoir simulation to investigate the feasibility of steam flooding to improve oil recovery in a light oil reservoir," In: North Africa Technical Conference and Exhibition, Cairo, Egypt 2013.

[3] M. Ashrafi, Y. Souraki, T.J. Veraas, H. Karimaie, and O. Torsaeter, "Experimental and numerical investigation of steam flooding in heterogeneous porous media containing heavy oil," In: SPE Asia Pacific Oil and Gas Conference and Exhibition, Jakarta, Indonesia, 2011.

[4] A.A. Awotunde, M.S. Azad, and C.N. Suarez, "Steam drive in naturally fractured reservoirs: a global optimization strategy," In: SPE Latin America and Caribbean Petroleum Engineering Conference, 2014.

[5] K. Dehghani, W.M. Basham, L.J. Durlofsky, and K.E. Tucker, "Modeling scale up of steamflood in a heterogeneous reservoir," SPE Reservoir Engineering, vol. 10, 1995.

[6] W. Sheng, Q. Yantao, and H. Chunping, "Influencing factors study on oil displacement efficiency after steam stimulation in heavy oil reservoir," Petroleum Geology and Recovery Efficiency, vol. 18, pp. 48-50, 2011.

[7] Q. Yaguang, A. Guirong, D. Zupeng, and Z. Wei, "Influence of plane heterogeneity on steam flooding development effect of heavy oil reservoirs," Journal of Xi'an Shiyou University, vol. 29, pp. 5558, 2014.

[8] Z. Ying, S. Yang, S. Hongan, and C. Dongxia, "Peculiarity analysis of heavy oil recovery by converting to steam flooding," Special oil and Gas Reservoir, vol. 16, pp. 62-66, 2009.

[9] S. Malik, E. Zhang, M.A. Asimi, and T.L. Gould, "Steamflood with vertical injectors and horizontal producers in multiple zones," SPE Reservoir Evaluation \& Engineering, vol. 14, 2011.

[10] W.T. Osterloh, D.S. Mims, and W.S. Meddaugh, "Probabilistic forecasting and model validation for the first-Eocene large-scale pilot steamflood, partitioned zone, Saudi Arabia and Kuwait," SPE Reservoir Evaluation \& Engineering, vol. 16, pp. 97-116, 2013.

[11] R.R.G.G. Godderij, J. Bruining, and J. Molenaar, "A Fast 3-D Interface Simulator for Steam Drives," In: SPE Western Regional Meeting, Long Beach, California, 1997.

[12] B. Yuhu, and Z. Jifu, "The advance in the scaling criteria of physical simulation for the complex flows system in reservoir," Advances in Mechanis, vol. 39, pp. 58-68, 2009.

\footnotetext{
Received: May 26, 2015

Revised: July 14, 2015

Accepted: August 10, 2015

(C) Jin et al.; Licensee Bentham Open.

This is an open access article licensed under the terms of the (https://creativecommons.org/licenses/by/4.0/legalcode), which permits unrestricted, noncommercial use, distribution and reproduction in any medium, provided the work is properly cited.
} 